\title{
PENENTUAN KRITERIA PENGHENTIAN ITERASI \\ PADA ALGORITMA STROBERI
}

\author{
Mutia Nur Estri \\ Universitas Jenderal Soedirman \\ mutia.estri@unsoed.ac.id
}

Siti Rahmah Nurshiami, Rina Reorita, Muhammad Okky Ibrohim

Universitas Jenderal Soedirman

\begin{abstract}
This paper discusses the application of two types of stopping criterion on the strawberry algorithm, which are stopping criteria based on iterative error and Cauchy criterion. Furthermore, the strawberry algorithm program is simulated on the optimization problem with the objective function is quadratic function. The simulation results on optimization problem with the objective function is quadratic function show that strawberry algorithm with stopping criterion based on Cauchy criterion has the best performance, when compared with stopping criterion based on iterative error and without stopping criterion.
\end{abstract}

Keywords: Cauchy criterion, quadratic function, optimization, stopping criterion, strawberry algorithm.

\begin{abstract}
ABSTRAK. Makalah ini membahas penerapan dua tipe kriteria penghentian iterasi pada algoritma stroberi, yaitu kriteria penghentian iterasi berdasarkan galat iteratif dan berdasarkan kriteria Cauchy. Selanjutnya algoritma stroberi tersebut disimulasikan pada permasalahan optimisasi dengan fungsi tujuan yang berupa fungsi kuadrat. Hasil simulasi pada permasalahan optimisasi dengan fungsi tujuan yang berupa fungsi kuadrat memperlihatkan bahwa untuk permasalahan optimisasi dengan fungsi tujuan yang berupa fungsi kuadratik, algoritma stroberi dengan kriteria penghentian iterasi berdasarkan kriteria Cauchy merupakan algoritma stroberi dengan hasil yang terbaik, jika dibandingkan dengan kriteria penghentian iterasi berdasarkan galat iteratif dan tanpa menggunakan kriteria penghentian.
\end{abstract}

Kata kunci: algoritma stroberi, fungsi kuadrat, kriteria Cauchy, kriteria penghentian iterasi, optimisasi.

\section{PENDAHULUAN}

Masalah optimisasi merupakan proses meminimasi atau memaksimasi suatu fungsi tujuan dengan memperhatikan kendala-kendala yang ada pada variabelnya (Nocedal dan Wright, 2006: 2). Masalah optimasi merupakan masalah penting di berbagai bidang, seperti teknik, industri, ekonomi dan kesehatan karena masalah 
optimasi ini merupakan masalah untuk mendapatkan solusi optimum yang terbaik.

Permasalahan optimisasi dapat diselesaikan dengan beberapa metode eksak atau hampiran. Salah satu metode hampiran yang digunakan untuk menyelesaikan permasalahan optimisasi adalah the plant propagation algorithm (PPA). Algoritma ini diperkenalkan pada tahun 2011 oleh Salhi dan Fraga. PPA sering disebut juga algoritma stroberi karena algoritma ini terinspirasi dari perkembangbiakan tanaman stroberi. Algoritma stroberi merupakan algoritma yang sederhana untuk dijelaskan dan diterapkan, serta memiliki parameter yang lebih sedikit dibandingkan algoritma metaheuristik yang lainnya (Sulaiman, dkk., 2014: 1).

Pada algoritma stroberi yang diberikan oleh Salhi dan Fraga (2011), pencarian solusi ditentukan oleh banyaknya generasi (iterasi). Ini berarti, meskipun sudah didapatkan populasi yang merupakan solusi optimum, iterasi akan terus berjalan sebanyak generasi yang telah ditentukan. Hal ini tentunya kurang efektif mengingat suatu algoritma sebaiknya dihentikan saat sudah mendapatkan hasil terbaiknya. Dengan demikian, perlu dilakukan modifikasi pada algoritma stroberi yang diberikan oleh Salhi dan Fraga agar iterasinya berhenti pada saat sudah didapatkan populasi yang merupakan solusi optimum. Salah satunya dapat dilakukan dengan menerapkan kriteria penghentian iterasi. Pada makalah ini kriteria penghentian yang digunakan adalah kriteria penghentian iterasi berdasarkan galat iteratif dan berdasarkan kriteria Cauchy.

Tipe-tipe kriteria penghentian iterasi tersebut diterapkan untuk memodifikasi algoritma stroberi. Selanjutnya program tersebut digunakan untuk melakukan simulasi permasalahan optimisasi dengan fungsi tujuan berupa fungsi kuadrat. Hasil simulasi kemudian dibandingkan, untuk mengetahui kriteria penghentian iterasi yang terbaik.

\section{METODE PENELITIAN}

Metode yang digunakan dalam penelitian ini adalah dengan studi pustaka, yaitu dengan mempelajari terlebih dahulu algoritma stroberi, mengkaji tipe-tipe 
kriteria penghentian iterasi. Selanjutnya memodifikasi algoritma stroberi yang sudah ada, yaitu dengan menambahkan kriteria penghentian iterasi. Hasil modifikasi kemudian digunakan untuk simulasi permasalahan optimisasi dengan fungsi tujuan berupa fungsi kuadrat. Kemudian, menghitung galat relatif antara solusi hampiran dan solusi eksaknya, yang diperoleh dengan program uji turunan kedua yang diberikan oleh Awalina (2016), pada setiap permasalahan optimisasi yang disimulasikan. Terakhir membandingkan hasil algoritma stroberi tanpa kriteria penghentian iterasi dan program algoritma dengan kriteria penghentian iterasi berdasarkan perolehan galat relatif dan waktu komputasi pada setiap permasalahan optimisasi yang disimulasikan.

\section{HASIL DAN PEMBAHASAN}

\subsection{Kriteria Penghentian Iterasi}

Pada makalah ini kriteria penghentian iterasi yang digunakan adalah:

1. Kriteria Penghentian Iterasi Berdasarkan Galat Iteratif

Galat iteratif adalah selisih perkiraan solusi iterasi sekarang dengan perkiraan solusi iterasi sebelumnya, yang disebut sebagai galat iteratif (Triatmodjo, 2008: 4). Rumus galat iteratif adalah

$$
E^{(k)}=\left|p^{(k)}-p^{(k-1)}\right|
$$

dengan

$$
\begin{aligned}
& E^{(k)} \quad \text { : galat iteratif pada iterasi ke- } k \\
& p^{(k)} \quad: \text { nilai solusi hampiran terbaik iterasi ke- } k \text { (iterasi saat ini) } \\
& p^{(k-1)}: \text { nilai solusi hampiran terbaik iterasi ke- }(k-1) \text { (iterasi sebelumnya). }
\end{aligned}
$$

\section{Kriteria Penghentian Iterasi Berdasarkan Kriteria Cauchy}

Kriteria Cauchy digunakan untuk memeriksa jarak dua barisan solusi hampiran dengan cara menghitung norm dari selisih dua barisan tersebut dan kemudian membandingkannya dengan sebuah nilai toleransi (e) (Cannas, 2016: 34). Barisan solusi pada algoritma iteratif sering disebut sebagai vektor solusi. Rumus galat iteratif berdasarkan kriteria Cauchy adalah 


$$
E_{c}^{(k)}=\left\|\mathbf{y}^{(k)}-\mathbf{y}^{(k-1)}\right\|
$$

dengan

$E_{c}^{(k)} \quad$ : galat iteratif Cauchy pada iterasi ke- $k$

$\mathbf{y}^{(k)} \quad$ : vektor solusi hampiran iterasi ke- $k$ (iterasi saat ini)

$\mathbf{y}^{(k-1)}$ : vektor solusi hampiran iterasi ke-(k-1) (iterasi sebelumnya).

Pada rumus (2), definisi norm yang digunakan merupakan jarak Euclid dua vektor solusi dari dua iterasi yang berdekatan, yang dirumuskan sebagai berikut

$$
\left\|\mathbf{y}^{(k)}-\mathbf{y}^{(k-1)}\right\|=\sqrt{\sum_{i=1}^{n}\left(y_{i}^{(k)}-y_{i}^{(k-1)}\right)^{2}} .
$$

\subsection{Penerapan Kriteria Penghentian Iterasi pada Algoritma Stroberi}

Penerapan kriteria penghentian iterasi dilakukan dengan cara memodifikasi algoritma stroberi. Modifikasi tersebut selanjutnya diterapkan pada program algoritma stoberi yang diberikan oleh Salhi dan Fraga (2011).

1. Penerapan Kriteria Penghentian Berdasarkan Galat Iteratif

Modifikasi dilakukan dengan menambahkan kondisi apakah galat iteratif sudah kurang dari nilai toleransi atau belum. Selengkapnya, dapat dilihat pada Gambar 1.

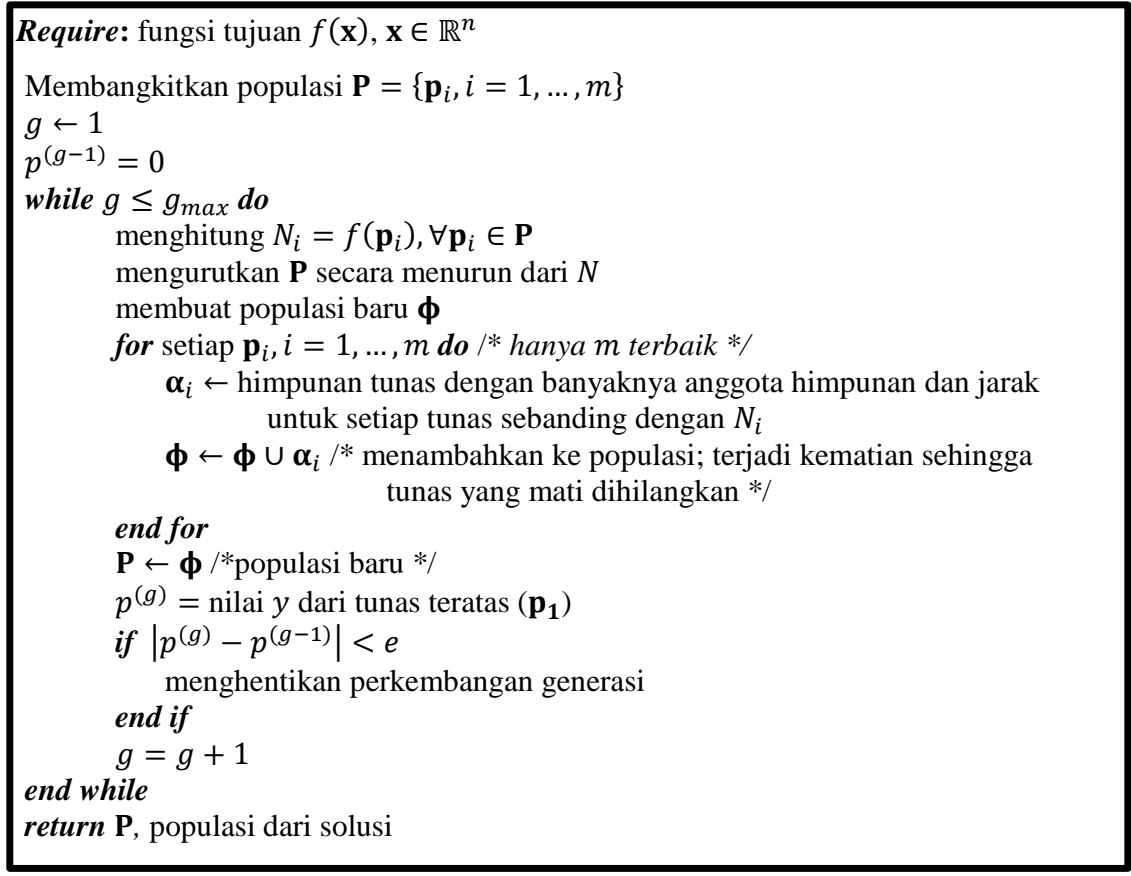

Gambar 1 Algoritma stroberi dengan kriteria penghentian berdasarkan galat iteratif 


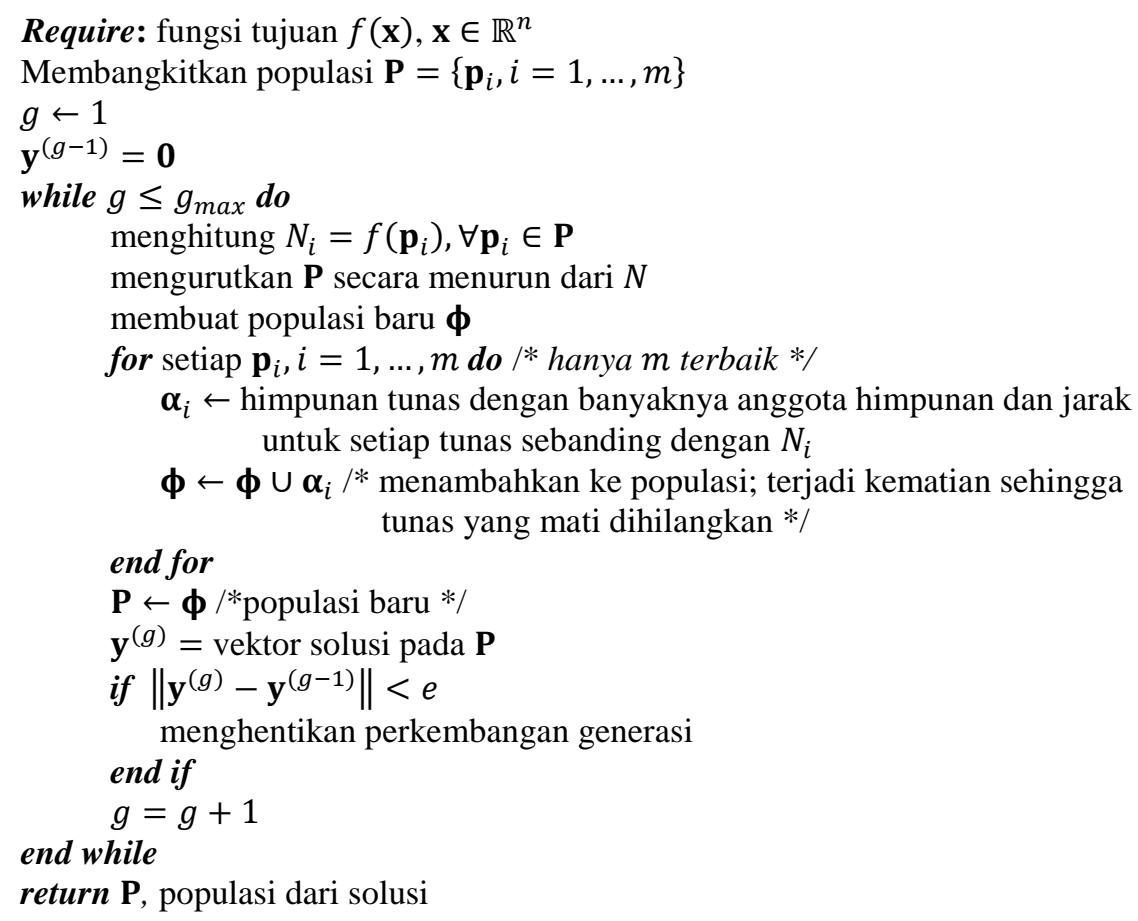

Gambar 2. Algoritma stroberi dengan kriteria penghentian berdasarkan kriteria Cauchy

\section{Penerapan Kriteria Penghentian Berdasarkan Kriteria Cauchy}

Secara umum, penerapan kriteria penghentian berdasarkan kriteria Cauchy pada algoritma stroberi analog dengan penerapan kriteria penghentian berdasarkan galat iteratif. Hal yang membedakan adalah rumus yang digunakan. Algoritma stroberi dengan kriteria penghentian berdasarkan kriteria Cauchy digambarkan pada Gambar 2.

\subsection{Hasil Simulasi Algoritma stroberi pada Permasalahan Optimisasi dengan Fungsi Tujuan Berupa Fungsi Kuadrat}

Permasalahan optimisasi yang akan disimulasikan pada makalah ini terdiri dari 5 kasus maksimasi dan 5 kasus minimasi. Selanjutnya, hasil simulasi tersebut dibandingkan dengan nilai eksaknya yang diperoleh menggunakan program uji turunan kedua sedemikian sehingga dapat dilihat tipe kriteria penghentian iterasi terbaik pada setiap contoh kasus yang diberikan. 


\subsubsection{Hasil Simulasi untuk Kasus Maksimasi}

Pada makalah ini, akan disimulasikan 5 kasus maksimasi pada fungsi kuadrat. Hasil simulasi kemudian dibandingkan dengan nilai eksaknya yang diperoleh menggunakan program uji turunan kedua (Awalina, 2016). Fungsifungsi kuadrat tersebut yaitu:

1. $f\left(x_{1}, x_{2}\right)=-4,63 x_{1}{ }^{2}-4,01 x_{2}{ }^{2}-1,90 x_{1}+0,96 x_{2}-2,94 x_{1} x_{2}+57,94$

(Estiasih, 2010);

2. $f\left(x_{1}, x_{2}\right)=-x_{1}{ }^{2}-x_{2}{ }^{2}+2 x_{1}+4 x_{2}-3$ (Ayres dan Mendelson, 2006: 324);

3. $f\left(x_{1}, x_{2}\right)=-x_{1}{ }^{2}-2 x_{2}{ }^{2}+6 x_{1}-4 x_{2}$ (Leithold, 1991: 383);

4. $f\left(x_{1}, x_{2}\right)=-2 x_{1}{ }^{2}-3 x_{2}{ }^{2}+88 x_{1}+114 x_{2}-4 x_{1} x_{2} \quad$ (Leithold, 1991: 387);

5. $f\left(x_{1}, x_{2}\right)=-x_{1}{ }^{2}-x_{2}{ }^{2}+6 x_{1}+8 x_{2}-21$

(Barnett, dkk., 2011: 470).

Nilai-nilai input yang digunakan pada kasus maksimasi disajikan pada Tabel 1. Hasil solusi eksak dan hampiran terbaik pada fungsi-fungsi yang disimulasikan dari setiap kriteria penghentian iterasi yang digunakan dan perbandingan waktu komputasi algoritma stroberi tanpa kriteria penghentian iterasi dan dengan kriteria penghentian iterasi diberikan pada Tabel 2.

Tabel 1. Nilai input untuk kasus maksimasi

\begin{tabular}{|c|l|c|c|}
\hline No. & Nama Input & Input & Nilai \\
\hline 1 & Fungsi tujuan & $f$ & $f$ \\
\hline 2 & Batas bawah domain & $\mathbf{a}$ & {$\left[\begin{array}{ll}-30 & -30]\end{array}\right.$} \\
\hline 3 & Batas atas domain & $\mathbf{b}$ & {$[3030]$} \\
\hline 4 & Lokasi awal peubah bebas & $\mathbf{x}_{1}$ & {$\left[\begin{array}{ll}0 \\
1\end{array}\right]$} \\
\hline 5 & Banyaknya generasi & $n g e n$ & 20 \\
\hline 6 & Ukuran populasi & npop & 5 \\
\hline 7 & Jumlah stolon maksimum & $k$ & 10 \\
\hline 8 & Banyaknya iterasi & $e$ & $10^{-4}$ \\
\hline 9 & Nilai toleransi & & \\
\hline
\end{tabular}


Tabel 2. Hasil solusi eksak dan hampiran terbaik algoritma stroberi untuk kasus maksimasi

\begin{tabular}{|c|c|c|c|c|c|c|c|}
\hline \multirow{3}{*}{$\begin{array}{c}\text { Fungsi } \\
\text { Tujuan }\end{array}$} & \multirow{3}{*}{$\begin{array}{c}\text { Nilai } \\
\text { Eksak }\end{array}$} & \multicolumn{3}{|c|}{ Hasil Solusi Hampiran Algoritma stroberi } & \multicolumn{3}{|c|}{$\begin{array}{l}\text { Waktu Komputasi Algoritma stroberi } \\
\text { (Detik) }\end{array}$} \\
\hline & & \multirow{2}{*}{$\begin{array}{c}\text { Tanpa } \\
\text { Kriteria } \\
\text { Penghentian } \\
\text { Iterasi }\end{array}$} & \multicolumn{2}{|c|}{$\begin{array}{c}\text { Dengan Kriteria } \\
\text { Penghentian Iterasi }\end{array}$} & \multirow{2}{*}{$\begin{array}{c}\text { Tanpa } \\
\text { Kriteria } \\
\text { Penghentian } \\
\text { Iterasi }\end{array}$} & \multicolumn{2}{|c|}{$\begin{array}{c}\text { Dengan Kriteria } \\
\text { Penghentian Iterasi }\end{array}$} \\
\hline & & & $\begin{array}{l}\text { Galat } \\
\text { Iteratif }\end{array}$ & $\begin{array}{l}\text { Kriteria } \\
\text { Cauchy }\end{array}$ & & $\begin{array}{l}\text { Galat } \\
\text { Iteratif }\end{array}$ & $\begin{array}{l}\text { Kriteria } \\
\text { Cauchy }\end{array}$ \\
\hline Maksimasi 1 & 58,144 & 58,143 & 57,9400 & 58,1438 & 0,4791 & 0,0486 & 0,3632 \\
\hline Maksimasi 2 & 2,000 & 1,999 & 1,3677 & 1,9999 & 0,4689 & 0,0365 & 0,3876 \\
\hline Maksimasi 3 & 11,000 & 10,999 & 10,2303 & 10,9999 & 0,4898 & 0,0240 & 0,4610 \\
\hline Maksimasi 4 & 1137,0 & 1137,000 & 1133,9000 & 1137,0000 & 0,5309 & 0,0275 & 0,5205 \\
\hline Maksimasi 5 & 4,000 & 3,999 & 3,7503 & 3,9999 & 0,5277 & 0,0350 & 0,5049 \\
\hline
\end{tabular}

Selanjutnya dapat dihitung galat relatif pada setiap solusi hampiran terbaik yang dihasilkan oleh algoritma stroberi. Nilai galat relatif pada setiap solusi hampiran terbaik yang dihasilkan oleh algoritma stroberi dapat dilihat pada Tabel 3.

Tabel 3. Nilai galat relatif untuk kasus maksimasi

\begin{tabular}{|c|r|r|r|}
\hline \multirow{2}{*}{$\begin{array}{c}\text { Fungsi } \\
\text { Tujuan }\end{array}$} & \begin{tabular}{c} 
Nilai Galat Relatif (\%) \\
Tanpa Kriteria \\
\cline { 2 - 4 }
\end{tabular} & $\begin{array}{c}\text { Dengan Kriteria } \\
\text { Penghentian Iterasi } \\
\text { Berdasarkan Galat } \\
\text { Iteratif }\end{array}$ & $\begin{array}{c}\text { Dengan Kriteria } \\
\text { Penghentian Iterasi } \\
\text { Berdasarkan Kriteria } \\
\text { Cauchy }\end{array}$ \\
\hline Maksimasi 1 & 0,0002 & 0,3507 & 0,0002 \\
\hline Maksimasi 2 & 0,0050 & 31,6150 & 0,0050 \\
\hline Maksimasi 3 & 0,0009 & 6,9973 & 0,0009 \\
\hline Maksimasi 4 & 0,0000 & 0,2726 & 0,0000 \\
\hline Maksimasi 5 & 0,0025 & 6,2425 & 0,0025 \\
\hline
\end{tabular}

Berdasarkan perolehan nilai galat relatif yang disajikan pada Tabel 3, terlihat bahwa galat relatif dari setiap solusi hampiran terbaik yang dihasilkan oleh program algoritma stoberi tanpa kriteria penghentian iterasi dan program algoritma stoberi dengan kriteria penghentian iterasi berdasarkan kriteria Cauchy relatif sangat kecil, yang mengimplikasikan bahwa kedua algoritma stroberi tersebut baik digunakan untuk menyelesaikan kasus maksimasi dengan fungsi tujuan yang diberikan. Namun, jika dilihat dari waktu komputasinya (yang disajikan pada Tabel 2), waktu komputasi yang dihasilkan oleh algoritma stroberi dengan kriteria penghentian iterasi berdasarkan kriteria Cauchy relatif lebih cepat dari algoritma stroberi tanpa kriteria penghentian iterasi. Ini berarti, kriteria penghentian iterasi berdasarkan kriteria Cauchy baik untuk diterapkan pada 
algoritma stroberi apabila digunakan untuk menyelesaikan kasus maksimasi pada fungsi tujuan yang diberikan. Sebaliknya, untuk algoritma stroberi dengan kriteria penghentian iterasi berdasarkan galat iteratif, meskipun waktu komputasi yang dihasilkan relatif lebih cepat dari kedua algoritma stroberi lainnya, namun galat relatif yang diperoleh relatif sangat besar dibandingkan galat relatif pada kedua algoritma stroberi lainnya. Ini berarti, kriteria penghentian iterasi berdasarkan galat relatif kurang baik untuk diterapkan pada algoritma stroberi apabila digunakan untuk menyelesaikan kasus maksimasi pada fungsi tujuan yang diberikan.

\subsubsection{Hasil Simulasi untuk Kasus Minimasi}

Fungsi tujuan yang akan disimulasikan pada kasus minimasi ada sebanyak 5 kasus. Hasil simulasi kemudian dibandingkan dengan nilai eksaknya yang diperoleh menggunakan program uji turunan kedua (Awalina, 2016). Fungsifungsi kuadrat tersebut yaitu:

1. $f\left(x_{1}, x_{2}\right)=x_{1}{ }^{2}+x_{2}{ }^{2}-x_{1}-2 x_{2}+36$

(Barnett, dkk., 2011: 470);

2. $f\left(x_{1}, x_{2}\right)=2 x_{1}{ }^{2}+3 x_{2}{ }^{2}-16 x_{1}-18 x_{2}+2 x_{1} x_{2}+54$

(Barnett, dkk., 2011: 474);

3. $f\left(x_{1}, x_{2}\right)=x_{1}{ }^{2}+x_{2}{ }^{2}-4 x_{1}+6 x_{2}+25$ (Ayres dan Mendelson, 2006: 322);

4. $f\left(x_{1}, x_{2}\right)=x_{1}{ }^{2}+x_{2}{ }^{2}-2 x_{1}-6 x_{2}+14$

(Stewart, 2003: 398);

5. $f\left(x_{1}, x_{2}\right)=6 x_{1}{ }^{2}+6 x_{2}{ }^{2}+36 x_{1}+6 x_{1} x_{2}-5$

(Lial, dkk., 1993: 431).

Nilai-nilai input yang digunakan pada kasus minimasi sama dengan pada kasus maksimasi, seperti disajikan pada Tabel 1. Hasil solusi eksak dan hampiran terbaik dari setiap fungsi yang disimulasikan pada kasus minimasi dan perbandingan waktu komputasi algoritma stroberi tanpa kriteria penghentian iterasi dan dengan kriteria penghentian iterasi untuk kasus minimasi diberikan pada Tabel 4. 
Tabel 4. Hasil solusi eksak dan hampiran terbaik program algoritma stroberi untuk kasus minimasi

\begin{tabular}{|c|c|c|c|c|c|c|c|}
\hline \multirow{3}{*}{$\begin{array}{l}\text { Fungsi } \\
\text { Tujuan }\end{array}$} & \multirow{3}{*}{$\begin{array}{l}\text { Nilai } \\
\text { Eksak }\end{array}$} & \multicolumn{3}{|c|}{$\begin{array}{c}\text { Hasil Solusi Hampiran Algoritma } \\
\text { stroberi }\end{array}$} & \multicolumn{3}{|c|}{ Waktu Komputasi Algoritma stroberi (Detik) } \\
\hline & & \multirow{2}{*}{$\begin{array}{c}\text { Tanpa } \\
\text { Kriteria } \\
\text { Penghentian } \\
\text { Iterasi }\end{array}$} & \multicolumn{2}{|c|}{$\begin{array}{c}\text { Dengan Kriteria } \\
\text { Penghentian Iterasi } \\
\text { Berdasarkan }\end{array}$} & \multirow{2}{*}{$\begin{array}{c}\text { Tanpa } \\
\text { Kriteria } \\
\text { Penghentian } \\
\text { Iterasi }\end{array}$} & \multicolumn{2}{|c|}{$\begin{array}{c}\text { Dengan Kriteria Penghentian } \\
\text { Iterasi Berdasarkan }\end{array}$} \\
\hline & & & $\begin{array}{l}\text { Galat } \\
\text { Iteratif }\end{array}$ & $\begin{array}{l}\text { Kriteria } \\
\text { Cauchy }\end{array}$ & & $\begin{array}{l}\text { Galat } \\
\text { Iteratif }\end{array}$ & $\begin{array}{l}\text { Kriteria } \\
\text { Cauchy }\end{array}$ \\
\hline Minimasi 1 & 10,0000 & 10,0001 & 11,1257 & 10,0001 & 0,5210 & 0,0392 & 0,4994 \\
\hline Minimasi 2 & 12,0000 & 12,0001 & 12,5924 & 12,0001 & 0,5336 & 0,0332 & 0,4983 \\
\hline Minimasi 3 & 12,0000 & 12,0001 & 12,5692 & 12,0001 & 0,4824 & 0,0437 & 0,4041 \\
\hline Minimasi 4 & 4,0000 & 4,0001 & 4,5661 & 4,0001 & 0,4812 & 0,0549 & 0,4120 \\
\hline Minimasi 5 & $-77,0000$ & $-76,9999$ & $-76,3147$ & $-76,9999$ & 0,4938 & 0,0355 & 0,4486 \\
\hline
\end{tabular}

Selanjutnya dapat dihitung galat relatif pada setiap solusi hampiran terbaik yang dihasilkan oleh algoritma stroberi. Nilai galat relatif pada setiap solusi hampiran terbaik yang dihasilkan oleh algoritma stroberi dapat dilihat pada Tabel 5 .

Tabel 5 Nilai galat relatif untuk kasus minimasi

\begin{tabular}{|c|r|r|r|}
\hline \multirow{2}{*}{$\begin{array}{c}\text { Fungsi } \\
\text { Tujuan }\end{array}$} & $\begin{array}{c}\text { Tanpa Kriteria } \\
\text { Penghentian } \\
\text { Iterasi }\end{array}$ & $\begin{array}{c}\text { Nilai Galat Relatif (\%) } \\
\text { Pengan Kriteria } \\
\text { Berdasarkan Galat } \\
\text { Iteratif }\end{array}$ & $\begin{array}{c}\text { Dengan Kriteria } \\
\text { Penghentian Iterasi } \\
\text { Berdasarkan Kriteria } \\
\text { Cauchy }\end{array}$ \\
\hline Minimasi 1 & 0,0010 & 11,2570 & 0,0010 \\
\hline Minimasi 2 & 0,0008 & 4,9366 & 0,0008 \\
\hline Minimasi 3 & 0,0008 & 4,7433 & 0,0008 \\
\hline Minimasi 4 & 0,0025 & 14,1525 & 0,0025 \\
\hline Minimasi 5 & 0,0001 & 0,8900 & 0,0001 \\
\hline
\end{tabular}

Berdasarkan perolehan nilai galat relatif yang disajikan pada Tabel 5, terlihat bahwa galat relatif dari setiap solusi hampiran terbaik yang dihasilkan oleh program algoritma stoberi tanpa kriteria penghentian iterasi dan program algoritma stoberi dengan kriteria penghentian berdasarkan kiteria Cauchy relatif sangat kecil, yang mengimplikasikan bahwa kedua algoritma stroberi tersebut baik apabila digunakan untuk menyelesaikan kasus minimasi dengan fungsi tujuan yang diberikan. Namun, jika dilihat dari waktu komputasinya (yang disajikan pada Tabel 4), waktu komputasi yang dihasilkan oleh algoritma stroberi dengan kriteria penghentian iterasi berdasarkan kriteria Cauchy relatif lebih cepat dari algoritma stroberi tanpa kriteria penghentian iterasi. Hal ini menunjukan 
bahwa kriteria penghentian berdasarkan kriteria Cauchy baik untuk diterapkan pada algoritma stroberi apabila digunakan untuk mencari solusi hampiran pada setiap kasus minimasi yang disimulasikan. Sebaliknya, untuk algoritma stroberi dengan kriteria penghentian berdasarkan galat iteratif, meskipun waktu komputasi yang dihasilkan relatif lebih cepat dari kedua algoritma stroberi lainnya, namun galat relatif yang diperoleh relatif sangat besar dibandingkan dengan galat relatif pada kedua algoritma stroberi lainnya. Ini berarti, kriteria penghentian berdasarkan galat iteratif kurang baik untuk diterapkan pada algoritma stroberi apabila digunakan untuk mencari solusi hampiran dari setiap kasus minimasi pada fungsi tujuan yang diberikan.

\section{KESIMPULAN DAN SARAN}

Berdasarkan hasil simulasi, galat relatif dari setiap solusi hampiran terbaik yang dihasilkan oleh algoritma stroberi tanpa kriteria penghentian iterasi dan dengan kriteria penghentian iterasi berdasarkan kriteria Cauchy relatif sangat kecil, yang mengimplikasikan bahwa kedua algoritma stroberi tersebut baik apabila digunakan untuk menyelesaikan kasus maksimasi dan minimasi pada setiap fungsi tujuan yang diberikan pada makalah ini. Namun, jika dilihat dari waktu komputasinya, waktu komputasi yang dihasilkan oleh algoritma stroberi dengan kriteria penghentian berdasarkan kriteria Cauchy relatif lebih cepat dari algoritma stroberi tanpa kriteria penghentian iterasi. Hal ini menunjukkan bahwa kriteria penghentian berdasarkan kriteria Cauchy baik untuk diterapkan pada algoritma stroberi apabila digunakan untuk mencari solusi hampiran pada setiap kasus maksimasi dan kasus minimasi yang disimulasikan.

Untuk penelitian selanjutnya, penulis menyarankan perlunya penerapan kriteria penghentian iterasi pada algoritma untuk mencari solusi optimum dari permasalahan optimisasi dengan fungsi-fungsi tujuan lain, misalnya fungsi Griewank, fungsi Ackley, dan fungsi Rastrigin. Selain itu, algoritma stroberi dengan kriteria penghentian iterasi perlu dikembangkan lagi agar dapat digunakan untuk mencari solusi optimum pada kasus multi-objective. 


\section{UCAPAN TERIMAKASIH}

Terima kasih diucapkan kepada Dr. Idha Sihwaningrum, M.Sc.St. yang banyak memberikan masukan dan saran pada proses penyusunan makalah ini.

\section{DAFTAR PUSTAKA}

Awalina, A. S., Algoritma Stroberi: Kajian dan Aplikasinya Pada Fungsi Kuadrat, Skripsi, Universitas Jenderal Soedirman, 2016.

Ayres, F., dan Mendelson, E., Kalkulus, Edisi ke-4, Erlangga, Jakarta, 2006.

Barnett, R. A., Ziegler M. R., dan Byleen, K. E., Calculus for Business, Economics, Life Sciences, and Social Sciences, Edisi ke-12, Prentice Hall, New York, 2011

Cannas, E. D., Parallel Computing: A Comparative Analysis Using Matlab, Tesis, Universita Degli Studi Di Cagliari, Clagiari, 2016.

Estiasih, T., Optimasi Kristalisasi Urea pada Pembuatan Asam Lemak $\omega-3$ dari Minyak Hasil Samping Penepungan Ikan Lemuru (Sardinella longiceps), Jurnal Teknologi Pertanian, 11 (2010), 37-46.

Leithold, L., Kalkulus dan Ilmu Ukur Analitik Jilid 3, Edisi ke-5, Erlangga, Jakarta, 1991.

Lial, M. L., Miller, C. D., dan Greenwell, R. N., Calculus with Applications, Edisi ke-5, HarperCollins College Publisher, New York, 1993.

Nocedal, J. dan Wright, S. J., Numerical Optimization, Springer Science and Business Media, New York, 2006.

Salhi, A. dan Fraga, E. S., Nature-Inspired Optimisastion Approaches and the New Plant Propagation Algorithm, Proceedings of The International Conference on Numerical Analysis and Optimization, Yogyakarta, 2011, 18.

Stewart, J., Kalkulus Jilid 2, edisi ke-4, Erlangga, Jakarta, 2003.

Sulaiman, M., Salhi, A., Selamoglu, B. I., dan Kirikchi, O. B., A Plant Propagation Algorithm for Constrained Engineering Optimisation Problems, Mathematical Problems in Engineering, Article ID 627416, 10 pages, 2014. Triatmodjo, B., Metode Numerik, Beta Offset, Yogyakarta, 2008. 
